\title{
Blended Learning on Students' Motivation: The Case of Teaching Solar System
}

\author{
Vania Zhafirah $^{1}$, Agus Fany Chandra Wijaya ${ }^{2}$, Nanang Winarno ${ }^{3}$ \\ \{Vaniazhafirah1@gmail.com ${ }^{1}$, Agus.fany@gmail.com², Nanang_winarno@upi.edu ${ }^{3}$ \} \\ Department of Science Education, Universitas Pendidikan Indonesia ${ }^{1}$ \\ Department of Physics Education, Universitas Pendidikan Indonesia ${ }^{2}$ \\ Department of Mathematics Education, Universitas Pendidikan Indonesia ${ }^{3}$
}

\begin{abstract}
Revolution industry 4.0 is related to technology, in which the internet and cloud computing create different opportunities and challenges for formal education systems. Blended Learning approach is one approach that combined online learning and face to face learning. This research aimed to investigate the profile of Blended Learning on students' motivation in learning the solar system. for 7th-grade students. This research uses a descriptive method. The research design used was the one-shot case study. The sample was taken from 7th-grade students in one of the secondary schools in Bandung, Indonesia. The sample consisted of 16 male students. The average score of students motivation that learning used Blended Learning is 68.88 and categorized as adequately. The percentage is $93.75 \%$ of students are categorized as adequately motivated and $6.25 \%$ of students categorized as highly motivated. The results showed that students have good motivation when using blended learning.
\end{abstract}

Keywords: Blended Learning, Students Motivation, Solar System

\section{Introduction}

Physics subject is one of many lessons that require the media to convey or explain the material [1]. Physics also requires students' experience. One of the roles of instructional media is giving students experiences that can not be obtained directly but it can be presented well using in the learning media. The main problem of teaching-learning of science especially in physics is generally unattractive. Hence, many students who lack an understanding of the physics concept become passive [2]. To handle this problem, interactive media makes students enjoying learn physics.

The development of the advance of technology is resulting in competition in life aspects. This competition requires some country to change its educational system that involves technology Motivation also needed to be enhanced in learning science. Therefore the lesson will not last transfer by verbal knowledge. Motivation can encourage students to learn or independently. Students will not interest in learning science if the motivation is absent. This is because when the students are highly motivated is tend to show more academic efforts and achievements than the students who low motivated in classroom activity and their tasks [3]. It can be seen based on the observation that doing in the class by the researcher and based on the interview with the teacher, it found that most of the students in that school have a problem in 
the physics subject. And it is found that students in that school are closed with technology in their teaching-learning process.

In the learning process. The computer simulation as an E-learning (electronic learning) is one kind of tools that are always used in the teaching process to improve students understanding in difficult concept at the lesser time than traditional method [4]. The computer simulation is computer-generated dynamics models that can explain the concept or simplified model of the real-world component, phenomena, or process of concept consisting of animation, visualization, and interactive laboratory experience [5].

E-learning as 'an innovative approach for delivering well-designed, learner-centered, interactive, and facilitated learning environment to anyone, anyplace, anytime by utilizing the attributes and resources of various digital technologies along with other forms of learning materials suited for open, flexible, and distributed learning environment [6]. This was an online space where students could interact with learning materials and with each other but without the physical presence of the instructor. On the other hand, traditional face-to-face learning helps in developing a strong value system. Some social skills are more easily developed in traditional or face to face learning. And those several skills are needed for facing this 21 st century [7].To combine both of face to face learning and E-learning known as Blended Learning. Blended Learning can also be defined as integrating face to face learning and electronic learning or distance learning, using different learning theories, methodologies, and techniques in the same place and supporting the learning with various online technologies during the learning process in the classroom [8]. Google Classroom which is a learning management system for schools that aims to simplify creating, distributing and grading assignments. The solar system topic is included in a concept in science that needs some media to help students understand the concept. The universe can not be seen directly to know all of the planets in our universe. Solar System Scope as one of the E-learning tools will be promoted as a technological media to help to learn Science. Solar system scope is an application on Android that provides the simulations of our universe. The $3 \mathrm{~S}$ Encyclopedia in Solar system scope will help the user to find out the most interesting fact about every planet by realistic 3D visualizations. To encourage exploration, this application also offers Nightsky Observatory, Scientific instruments, and unique maps with accurate maps are based on NASA elevation and imagery data.

In other research, that using Moodle (Modular Object-Oriented Dynamic Learning Environment) as an online classroom to analyzed student's' engagement and academic achievement, they stated that Blended Learning has had a positive effect on the active participation of students in courses and development of students' motivation towards the course [9]. According to research that measured an effect on students' achievement, motivation, collaboration and communication as perceived by students by using moodle [10]. It found that using Moodle in learning increased students' achievements and self-regulated skills. In another research which has the purpose to is to measure the effectiveness of a Blended Learning it found that a significant difference between students' view in relation with Blended Learning environment as well as online and face to face learning environments [11]. However, in this study, the researcher will combine the e-learning environment with utilized Google classroom features as a Learning Management System (LMS), solar system scope application as a teaching media, and face to face activities with discovery learning and station rotation as a form of Blended learning.

There were several studies about Blended Learning that already supported by another LMS or using another teaching model. However, the differences between this study and another study are the implementation of discovery learning and combined with station rotation 
as a form of Blended Learning in the face to face learning, the use of Google Classroom as LMS, and the use of Solar System Scope application as a teaching media and technology support. Several studies investigate the impact of Blended Learning to students' motivation. However, In other research no study investigates students motivation with six-factor, however, the researcher decides that this study is to investigate the profile of the use of Blended Learning on five-factor of motivation which is intrinsic motivation and personal relevance, self-efficacy, and assessment anxiety, self-determination, career motivation, and grade motivation. This research is suitable in this revolution industry 4.0 because involved some digital tools and the internet during the teaching-learning process.

\section{Research Method}

The study was conducted in Junior high school " $X$ " that was located in Bandung, Indonesia. This school was applied to Kurikulum 2013 in the teaching-learning process. The Population in this research was 7th-grade students with ages range between 13 until 14 years old. The samples are 7th-grade students from one class in secondary school " $X$ " that consists of 16 males. This research uses a descriptive method[12]. The sample was taken from 7thgrade students in one of the secondary schools in Bandung, Indonesia. That is related to the purpose of this study which is to investigate the profile of the implementation of Blended learning supported by the Solar System Scope app, discovery learning and Google Classroom towards students' motivation in learning the solar system. The One-Shot Case Study design is used in this research. In the one-shot case study design, a single group is exposed to a treatment or event and a dependent variable is subsequently observed(measured) to assess the effect of the treatment. A posttest is a measure on some attribute or characteristic that is assessed for participants in an experiment after a treatment which is Blended Learning.

The sampling technique that is used for this research was convenience sampling. A convenience sample is a group of individuals who (conveniently) are available for study [12]. The researcher selects participants because they are willing and available to be studied. The researcher decides to study this group at this one school because they are available and because the researcher has the permission of the principal [13-14]. The students' motivation was measured by using the Science Motivation Questionnaire which was developed by Shawn M. Glynn, Gita Taasoobshirazi, and Peggy Brickman [15]. The questions in this research are20 questions divided into five dimensions. The options in the questionnaire are in the form of a Likert scale which has 5 choices in each question. For analyzing the questionnaire is used Microsoft office excel and calculated the interval for the interpretation.

The research was done in 3 three meetings. In three meetings the teaching-learning did by the implementation of Blended Learning by implementing the discovery learning model in face to face learning and supported by using of Solar System Scope, Google Classroom, and station rotation. The duration in one meeting is 120 minutes. In this research just use one group of experiments or without a control group. The experiment group uses Blended Learning as a model of learning. Station rotation that included the part of Blended Learning. The research was done in Junior high school " $\mathrm{X}$ " in Bandung in April 2019 with the sample is the students from 7th-grade in one class. For all instructional process that was done in 3 meetings, for each meeting the duration was 120 minutes. A pre-test was held on $15^{\text {th }}$ April 2019 and for Post-test was held on $29^{\text {th }}$ April 2019. 
The teaching tool used in this experiment group by using the Solar System Scope as the E-learning for delivering material about the Solar system and use of Google Classroom for delivering materials and submit the homework online. Google classroom also used to deliver and distributed worksheets for the students. The implementation of Blended Learning was investigated by observation sheet during the lesson.

\section{Result and Discussion}

\subsection{The effect of Blended Learning on Students' Motivation}

The students' motivation was measured by using the Science Motivation Questionnaire which was developed by Shawn M. Glynn, Gita Taasoobshirazi, and Peggy Brickman [15]. The questionnaire is just given in the post-test when they already are given treatment. The questionnaire has been given to the students in the class using Google Form. To obtain the result of the questionnaire, the researcher was analyzed using Microsoft Excel 2013. Five dimensions measured in this research which are Intrinsic motivation and Personal Relevance, Self-efficacy and Assessment anxiety, Self-determination, Career motivation, and Grade motivation. The result of the questionnaire can be analyzed to determine students' motivation in learning the solar system topic by using Blended Learning and with the support of the Solar System Scope application. The options in the questionnaire are in the form of a Likert scale which has 5 choices in each question.

The categorization of students' motivation is based on the calculation of the students' scores. The categorization is divided into 3 categories if the total score $>73.4$ is categorized as high motivation If the total score between 46.7 - 73.4 is categorized as adequate motivation and If total score $<46.7$ is categorized as low motivation [15]. All of the questions have different statements, there are favorable questions and unfavorable questions. The average score of students' motivation score in this research is 68.875 and categorized as adequately. The result of Students' motivation in the whole class will be shown in the form of a chart that will be shown in Figure 1.

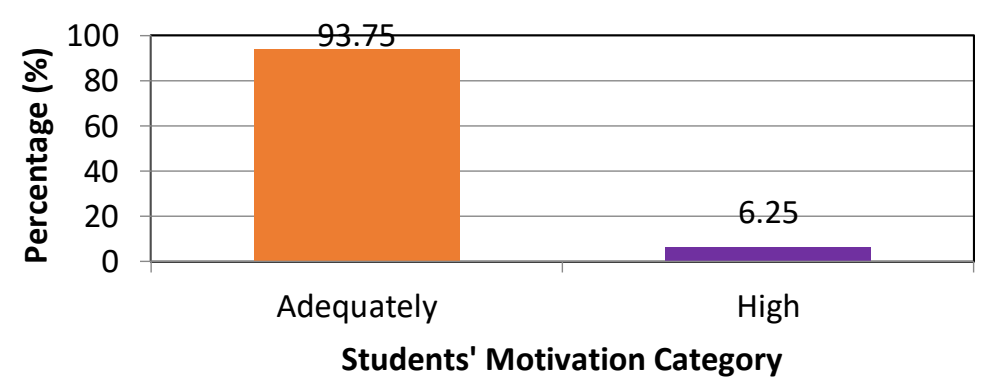

Fig. 1. The percentage of students' motivation.

Based on Figure 1 above it is know that there are 15 students from 16 participants categorized as Adequately in Motivation, And 1 student from 16 participants, which means just $6.25 \%$ categorized as high in motivation and the rest of it categorized as Adequately motivation. Some factors make the students in this research categorized as adequately 
motivated in this Blended learning environment with supported by some aspects, which are the use of discovery learning as a learning model, Solar System Scope as planetarium software to learn the solar system and Google Classroom as the LMS. The solar system topic also has content that is related to the explanation in the Qur'an verse. The explanation of the Qur'an verse is about Earth, Moon, Sun, and orbital among the planet is a logical mind for students. Before the teaching-learning process is started, students recite Al- Qur'an first that relate to solar system topic. Recite Al- Qur'an before staring the lesson could be the one factor that can enhance student's motivation because when they recite the meaning of the ayat, it's triggering some questions and motivated the students. The students were actively engaged in the group discussion with their peers and the teacher when clarified their understanding.

Blended learning in this has a positive impact on students' motivation. Students enjoy and active when the teaching-learning process held in the classroom. The combination of the e-learning environment makes students more motivated to learn because they can use their phone or Chromebook to learn and discover the application. This is in line with the previous research, According to their study, a high degree of utility, motivation, and satisfaction is perceived from Blended Learning, which could lead students to have a positive attitude towards learning [16]. Moreover, this conclusion indicates that Blended Learning reinforces students' understanding of the subject in question, enhancing and supporting the learning process [17]. Also, it is shown that the online activities included were useful for the students, which could have a favorable influence on the work they carried out independently.

This finding is in line with the previous study, he concludes that Blended Learning with increased support can improve module retention by motivating learners to complete coursework on time [18]. This can be seen from there are no students who collect their homework late through Google Classroom. This is also in line with the previous study done as the results show, the blended PBL helped to increase students' motivation [19]. This result also in line with the previous study they conclude that The Experimental Group Showed a Positive Learning Attitude, and Enhanced Their Learning Motivation[20].

The use of the discovery learning model during face to face learning in this blended learning environment gives a positive impact on the students' motivation. Students can freely seek and exploring some new information. With six syntaxes used in this research, it can make students more exciting to learn and tend to be more motivated to start the teaching-learning process because they can learn by their findings. This finding is in line with the previous study of the exercise, students found themselves engaged in cognitive activity [21]. The discovery learning model is a student-centered learning environment. It is defined by Cannon and Newble that student-centered as 'ways of thinking about teaching and learning that emphasize student responsibility and activity in learning rather than content or what the teachers are doing[22]. Based on the previous research,they stated that a student-centered form of learning can be more beneficial for students' motivation if granted autonomy is embedded in a supportive environment[23].

Besides discovery learning, the use of the Solar System Scope in this research also gives a positive impact to enhance students' motivation. Solar System Scope features allowed the students to can explore any object in outer space, allowed the students to observe the movement of the planet in their axis and stars in the solar system with detail. In the Solar System Scope application, there is a feature that can students used to see the condition of the arrangement due to the date it happens. So the student can set the time every time they want. They can see the phenomenon happen in the several days latter or several days ago. Solar System Scope application provides give some great virtualization and animation about planets and any other things in the solar system, for example, the structure of the planet, the 
composition, and their distances. It means that intrinsic motivation (motivation to engage in an activity for its own sake) and extrinsic motivation (motivation to engage in an activity as a means to an end) can be interactive. When students learn science, they can be motivated by different kinds of goals operating at the same time [24].

\subsection{The effect of Blended Learning on each dimension of Motivation}

There are 5 dimensions of motivation measured in this research which are Intrinsic motivation and Personal Relevance (Dimension 1), Self-efficacy and Assessment anxiety (Dimension 2), Self-determination (Dimension 3), Career motivation (Dimension 4) and Grade motivation (Dimension 5). To see the comparison between each Motivation dimension, the results will be shown in Figure 2.

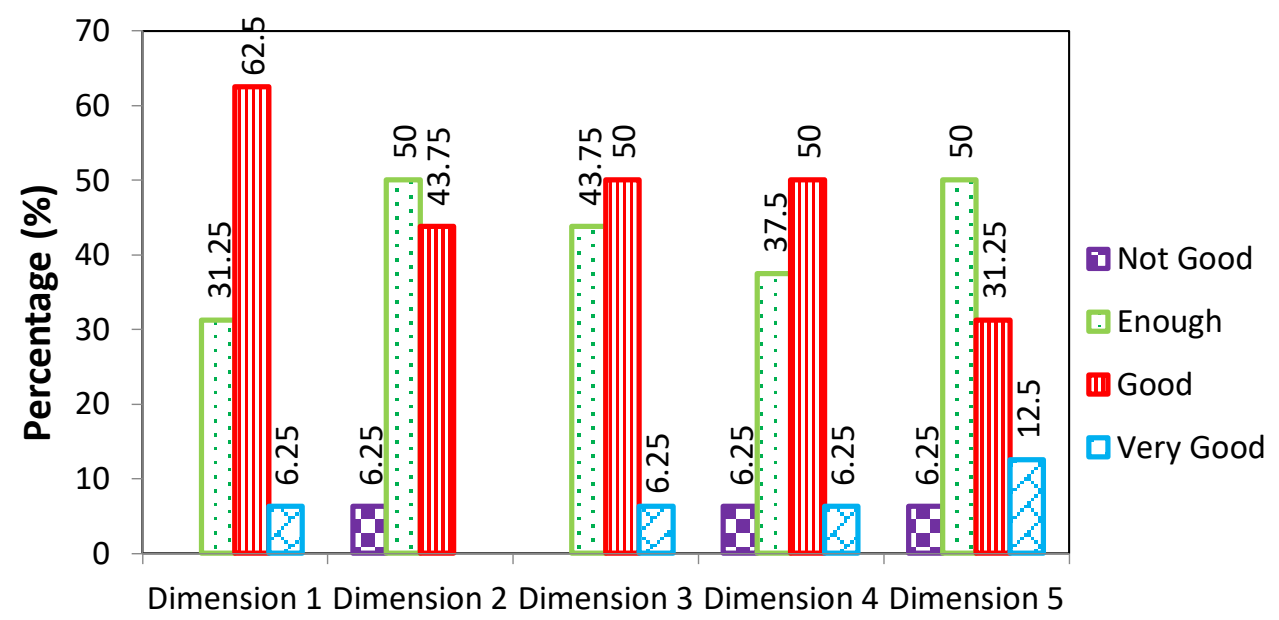

Fig. 2. Students‘ motivation comparison between each dimension.

Figure 2 shows the differences category that students got in each dimension. Three from five dimension results have high at Good category. The lowest in this motivation dimension is dimension three. As we can see that dimension one is the highest compared to the other dimension. Dimension 1 in this research is about Intrinsic motivation and self-relevance. In this dimension, there are $6.25 \%$ of students who categorized as very good motivation, as much as $62.5 \%$ of students categorized as good motivated and the last one as much as 31.25 $\%$ of students categorized as enough motivated. From here we can conclude that students in this experimental class have a good skill to relate materials into their real-life and they have a good motivation that comes from themselves.

The implementation of dimension 1 (self-relevance) is they can relate the knowledge that they already get into their daily life. For example, they will not confused about why on this earth happen day and night, they can answer it because it is one of the effects form rotation of the earth that they already lean in the teaching-learning process. The implementation of discovery learning makes students should discover the knowledge helps to make the knowledge more meaningful. Dimension three in this research is about self-determination. As 
much as $6.25 \%$ of students categorized as very motivated, $50 \%$ of students are categorized as good motivated and the last one as much as $4.75 \%$ of students categorized as enough motivated. Here we can see that students have a good determination by themself. Selfdetermination, which refers to the control students believe they have over their learning of science, So they based on the question and the answer form the students means that students are good to prepare learning science. The use of Google Classroom to delivering and managing the class is really helpful to this self-determination dimension. So wherever they want to learn and every time they want to learn some materials that already given by the teacher, they can prepare it before entering the class learn it via Google Classroom.

Dimension four is career motivation. Here we can conclude that students in this experiment class have good self-determination and also they have good career motivation for the future. Whether the students still in grade 7, it is very necessary to plan their future. Students in this experiment group have a good basic to knowing their career earlier. In the future when technology will fast improving, at least the students in this experiment group have a basic skill to operating and knowing the technology to prepare the future by getting used to Google Classroom feature and Solar System Scope application. For dimension one (intrinsic motivation and personal relevance) and dimension three (career motivation) in this research have a similar result which is both of this dimension have a lot of students categorized as highly motivated. Careers are often thought of as extrinsically motivating (money, social status, etc.), but they can be intrinsically motivating (interest, enjoyment, etc.) as well. It means that intrinsic motivation (motivation to engage in an activity for its own sake) and extrinsic motivation (motivation to engage in an activity as a means to an end) can be interactive.

\section{Conclusion}

Motivation is needed to be gained during the teaching-learning process in the classroom. Motivation and academic achievement have a relation in the teaching-learning process. when the students have high motivation, it tends to be more have academic effort and achievement. Based on the result of this research, here we can conclude that Blended Learning can enhance students' motivation. Supported by Google Classroom, Solar System Scope and Discovery learning model is helps to engaged student's motivation.

\section{References}

[1] Uzezi, J. G., \& Jonah, K. J.: Effectiveness of brain-based learning strategy on students' academic achievement, attitude, motivation and knowledge retention in electrochemistry. Journal of Education, Society and Behavioural Science, pp 1-13. (2017)

[2] Haya, F. D., Waskito, S., \& Fauzi, A.: Pengembangan Media Pembelajaran Gasik (Game Fisika Asik) Untuk Siswa Kelas VIII Sekolah Menengah Pertama. Jurnal Pendidikan Fisika, 2(1). (2014)

[3] Alsultanny, Y. A., Nouby, A. M., \& Al-Enazi, T. T.: Effects of using simulation in e-learning programs on misconceptions and motivations towards learning. International Journal of Science and Technology Education Research, 5(3), pp 40-51. (2014)

[4] Bell, R. L., \& Smetana, L. K.: Using computer simulations to enhance science teaching and learning. National Science Teachers Association, 3, 23-32. retrieved from www.researchgate.net[access on. 15th June 2019]. (2008) 
[5] Khan, B.: Managing e-learning strategies: design, delivery, implementation, and evaluation. Hershey, PA:Idea Group Inc. (2005)

[6] Dangwal, K. L.: Blended Learning: an innovative approach. Universal Journal of Educational Research, 5(1), pp 129-136. (2017)

[7] Rossett, A.: The ASTD e-learning handbook: Best practices, strategies, and case studies for an emerging field.McGraw-Hill Trade.. (2002)

[8] Saritepeci \& Cakir.: The effect of Blended Learning environments on student motivation and student engagement: A study on social studies course. Egitim ve Bilim, 40(177) pp 203-2016, (2015)

[9] Al-Ani, A., Alsukker, A., \& Khushaba, R. N.: Feature subset selection using differential evolution and a wheel based search strategy. Swarm and Evolutionary Computation, 9, 15-26. (2013)

[10] Eryilmaz, M: The Effectiveness of Blended Learning Environments. Contemporary Issues in Education Research, 8(4), pp 251-256.(2015).

[11] Fraenkel, J. R., Wallen, N. E., \& Hyun, H. H.: How to design and evaluate research in education. New York: McGraw-Hill (2011)

[12] Creswell, J. W.: A concise introduction to mixed methods research. SAGE publications.(2014)

[13] Glynn, Shawn.: et al:Science motivation questionnaire: Construct validation with nonscience majors. Journal of Research in Science Teaching: The Official Journal of the National Association for Research in Science Teaching, 46(2), pp127-146. (2009)

[14] Haryono, S.: Metode Sem Untuk Penelitian Manajemen: AMOS, LISREL \& PLS.(2017)

[15]López-Pérez, M. V., Pérez-López, M. C., \& Rodríguez-Ariza, L.: Blended Learning in higher education: Students' perceptions and their relation to outcomes. Computers \&Education,56(3),pp 818-826. (2011)

[16]Lei, J.: Quantity versus quality: a new approach to examining the relationship between technology use and student outcomes. British Journal of Educational Technology, 41(3), pp 455472.(2010)

[17] Hughes, G.: Using blended learning to increase learner support and improve retention. Teaching in Higher Education, 12(3), pp 349-363.(2007)

[18] Woltering, V., Herrler, A., Spitzer, K., \& Spreckelsen, C.: Blended learning positively affects students' satisfaction and the role of the tutor in the problem-based learning process: results of a mixed-method evaluation. Advances in Health Sciences Education, 14(5), pp 725.(2009)

[19] Chao, C. Y., Chen, Y. T., \& Chuang, K. Y.: Exploring students' learning attitude and achievement in flipped learning supported computer-aided design curriculum: A study in high school engineering education. Computer Applications in Engineering Education, 23(4), pp 514-526.(2015)

[20] Mukherjee, A.: Effective use of discovery learning to improve understanding of factors that affect quality. Journal of Education for Business, 90(8), pp 413-419. (2015)

[21] Newble, D. I., \& Cannon, R. A.: A handbook for medical teachers. Springer Science \& Business Media.(2001)

[22] Smit, K., de Brabander, C. J., \& Martens, R. L.: Student-centred and teacher-centered learning environment in pre-vocational secondary education: Psychological needs, and motivation. Scandinavian Journal of Educational Research, 58(6), pp 695-712.(2014)

[23] Black, A. E., \& Deci, E. L.: The effects of instructors' autonomy support and students' autonomous motivation on learning organic chemistry: A self-determination theory perspective. Science education, 84(6), pp 740-756.(2000)

[24] Pintrich, P. R.: A motivational science perspective on the role of student motivation in learning and teaching contexts. Journal of educational Psychology, 95(4), 667. (2003) 